\title{
Zonguldak Taş Kömürü Havzasında Yapılmış Radon Gazı Ölçümlerinin Değerlendirilmesi
}

\author{
Evaluation of the Radon Gas Levels Measured in Zonguldak Bituminous Coal Basin
}

\author{
Rıdvan BALDIK, Hüseyin AYTEKIN
}

\begin{abstract}
ÖZET
Radon doğada bulunan tek radyoaktif gaz olup doğal radyasyonun en önemli kaynağını oluşturmaktadır. Radon sigaradan sonra akciğer kanserine sebep olan ikinci önemli etkendir ve ikisinin birlikte olușturduğu akciğer kanser riski, ikisinin ayrı ayrı meydana getireceği riskten daha fazladır. Bu çalışmada, Zonguldak taşkömürü havzasında bulunan Üzülmez, Kozlu, Karadon, Armutçuk ve Amasra maden ocaklarında bazı araştırmacılar tarafından yapılmış radon gazı konsantrasyon ölçüm sonuçları ve radon gazı sebebiyle maruz kalınan radyasyonun zarar verme derecesi olan doz değerlerinin birlikte değerlendirilmesi ele alınmaktadır. Ayrıca radon gazı konsantrasyonları ve doz değerleri, yetkili kuruluşlar tarafından belirlenen limit değerleri ile karşılaștırılmıștır.
\end{abstract}

Anahtar Kelimeler: Zonguldak, Taşkömürü, Radon, Doz Değerlendirmeleri

\section{ABSTRACT}

Radon being unique radioactive gas in the nature which is the most important source of natural radiation. Radon is the second major cause of lung cancer after cigarettes and the two of them together caused the risk of cancer is more than those of the two of them separately. In this study, the radon concentrations and dose assessments for the Üzülmez, Kozlu, Karadon, Armutçuk ve Amasra mines in the Zonguldak bituminous coal basin that made by some researchers are evaluated. Also, the radon concentrations and the dose values are compared with the limit values that determined by regulatory bodies.

Keywords: Zonguldak, Bituminous Coal, Radon, Dose Assessments

Doç. Dr. Rıdvan BALDIK - Bülent Ecevit Üniversitesi, Fen Edebiyat Fakültesi, Zonguldak, Türkiye Assoc. Prof. Ridvan BALDIK - Bulent Ecevit University, Faculty of Arts and Sciences, Zonguldak, Turkey rbaldik@gmail.com

Prof. Dr. Hüseyin AYTEKiN - Bülent Ecevit Üniversitesi, Fen Edebiyat Fakültesi, Zonguldak, Türkiye Prof. Huseyin AYTEKIN - Bulent Ecevit University, Faculty of Arts and Sciences, Zonguldak, Turkey huseyinaytekin@gmail.com

*Bu çalışma, 11-13 Mayıs 2006 tarihleri arasında Zonguldak'ta gerçekleşen “II. Ulusal Mühendislik Kongresi”nde sunulmuştur. 


\section{GİRİŞ}

İnsanlar, hayatın bir parçası olarak atomları iyonlaştıracak seviyede enerjiye sahip iyonize radyasyona maruz kalmaktadırlar. İyonize radyasyonun biyolojik etkilerinin bir ölçüsü olan eşdeğer doz, kilogram başına soğurulan enerji olup birimi Sievert (Sv)'dır. 1 Sv çok yüksek bir değer olduğundan daha çok bunun binde biri olan mili Sievert $(\mathrm{mSv})$ birimi kullanılır. Ortamın fiziksel özellikleri ve coğrafi şartlara bağlı olarak değişiklik gösteren bu radyasyon türlerine maruz kalan insanlar yıllık 2.4 mili Sivert $(\mathrm{mSv})$ doza maruz kalmaktadırlar [1]. Bu dozun yaklaşık \% 85 doğal kaynaklardan (radon gazı, yeryüzü, kozmik ışınlar, su ve yiyecek) ve \% 15 lik (tıbbi uygulamalar, nükleer denemeler vb.) kısmı da yapay kaynaklardan gelmektedir. Doğal kaynakların \% 50' sini radon gazı ve onun kısa yarı ömürlü bozunma ürünleri oluşturmaktadır ve bunun doz olarak karşılığı yıllık 1.2 mSv'dir [1-3]. Radon renksiz, kokusuz ve doğada gaz olarak bulunan tek radyoaktif elementtir. Soy gazlar ailesine mensup radon gazı insan duyu organlarıla gözlenemediğinden varlığı ve şiddeti ancak özel olarak tasarlanmış cihazlar yardımıyla belirlenebilir.

Radon gazını ölçmek için aktif ve pasif ölçüm tekniği olmak üzere iki yöntem kullanılır. Anlık radon ölçümleri yapılmak istendiğinde aktif ölçüm tekniği kullanılmaktadır. Radon gazı nem, basınç, hava sıcaklığı vb. gibi etkilerden çok fazla etkilenir, bu da ardışı ölçümler sonucu farklı konsantrasyonlar elde edilmesine sebep olur $[3,4]$. Bu nedenle bu yöntem çok tercih edilmez. Ölçümler günlük, aylık, mevsimlik veya yıllık gibi uzun süreli yapılırsa ortalama bir radon konsantrasyonu bulanabilir. Ortalama bir radon konsantrasyonu elde etmek için pasif ölçüm tekniği kullanmak daha uygundur. Bu teknik, radon gazı ve ürünleri alfa yayınlayıcısı olduğundan, alfa parçacıklarının bir plastik plaka üzerine gözle görünmeyen izler bırakarak sayılması esasına dayanır. Bu görünmeyen izleri mikroskop altında görünür hale getirebilmek için Kimyasal İz Kazıma yöntemi kullanılır. Bu plakalara pasif nükleer iz dedektörleri denir $[1,3]$. Son yıllarda yapılan radon gazı ölçümlerinde ticari adı CR-39 olan "allil diglikol karbonat" plastik plakalar kullanılmaktadır. 10x10x1 mm boyutlarında hazırlanan bu CR-39 plakaları, plastik bir kabın kapağına yerleştirilerek kapak kapanır. Bu kapağın içerisi yalnızca havanın ve dolayısıyla radon gazının girebileceği şekilde tasarlanmış olması gerekmektedir [4].

Yerkabuğunda doğal olarak bulunan üç önemli radyoaktif element, uranyum $(\mathrm{U})$, toryum $(\mathrm{Th})$ ve potasyumdur (K). Uranyum ve toryum pek çok uzun yarı ömürlü radyoaktif elementin başlangıç kaynağını oluşturmaktadırlar. Bu iki radyoaktif elementin doğada oluşturdukları üç temel radyoaktif seri bulunmaktadır. Bunlar; ${ }^{238} \mathrm{U},{ }^{235} \mathrm{U}$ ve ${ }^{232} \mathrm{Th}$ radyoaktif bozunum serileridir. Bu serilerden ${ }^{238} \mathrm{U}$ bozunum serisinden gelen ve 3,82 gün yarı ömre sahip ${ }^{222 R n}$ (radon)'dır. Diğer iki seriden gelen ${ }^{220} \mathrm{Rn}$ ( ${ }^{232} \mathrm{Th}$ serisinden) ve ${ }^{219} \mathrm{Rn}\left({ }^{235} \mathrm{U}\right.$ serisinden) radon izotoplarının yarı-ömürleri sırasıyla 55.6 s ve 3.96 s olduğundan bunların atmosferik ortamlara kaçarak oluşturabilecekleri konsantrasyonlar düşüktür $[3,5]$. Bu sebeple, radon gazı denince akla ${ }^{222} \mathrm{Rn}$ radyoizotopu gelmelidir.

Radon, uranyumun mevcut olduğu tüm kaya ve toprağın bünyesinden difüzyon veya konveksiyonla sızarak atmosfere kaçma eğilimi göstermektedir [2]. Fakat bir kısmı yeralında kalır ve suda çözünerek yeraltı sularına karışmaktadır [3]. Atmosferik radon dağılımı meteorolojik koşullara göre değiş̧mektedir ve yükseklik arttıkça konsantrasyon değeri azalma eğilimi göstermektedir. Evlerdeki radonun kaynağı ise evlerin tabanında veya duvarlarında bulunan çatlak ve boşluklardan içeri gazın sızmasıdır. Bu sebeple, bodrum katlarda ve yeraltı maden ocaklarında radon gazının yoğunluğu daha fazladır [3]. 


\section{7}

Yeraltı kömür madenlerinde kayaç ve kömürün bünyesinde bulunan radyoaktif elementlerin bozunması sonucu oluşan radon gazı çatlak ve gözeneklere birikir ve maden ocağının havasına yayılır [6]. Yapılan çalışmalar uzun süre radon gazına maruz kalan kişilerin akciğer kanserine yakalanma riskinin yüksek olduğunu göstermektedir [7]. Bu sebeple, yeraltı kömür madenlerinin yüksek oranda radon gazı ihtiva etmesi bu ocaklarda çalışan işçilerin sağlığı açısından önemli bir mesleki risk oluşturmaktadır. Maden ocaklarında radon gazı kaynaklı alınan doz, maden ocağının türü, işçilerin çalışma süresi, çalışma tekniği ve ocağın havalandırması gibi parametrelerle ilişkilidir [6,8]. Burada bahsedilen parametreler ve radon gazı arasındaki ilişkinin araştırılması, özellikle, maden ocaklarında çalışanların sağlığı ve güvenliği açısından oldukça önemlidir. Dünyada ve ülkemizde bazı yeraltı kömür ocaklarında radon konsantrasyonları ve işçilerin aldıkları dozlar üzerine bazı araştırmalar yapılmıştır. Bu çalışmaların bazıları kaynakçada sunulmuştur [6,9-19].

\section{RADON VE AKCİĞER KANSERİ ARASINDAKİ İLIŞKİ}

Radon alfa yayınlayarak polonyum (Po), bizmut ( $\mathrm{Bi}$ ) ve kurşun $(\mathrm{Pb})$ radyoaktif elementlerine dönüşürler. Bu ürünlerin radondan farkı daha kısa yarıömürlü ve gaz olmamalarıdır. Bu katı radyoaktif elementler havadaki tozlara ve su damlacıklarına tutunarak radyoaktif aerosoller oluştururlar. $\mathrm{Bu}$ aeoroselleri taşıyan hava solunduğunda üst solunum yollarına tutunurlar. Bu aerosellerin bünyesindeki ürünlerin yarı ömrü birkaç saat ile bir gün arasında olduğundan yayınlanan tüm alfa parçacıkları enerjilerini akciğer hücrelerine aktararak hücreyi tahrip edebilirler. Bu etki akciğerde hasara ve dolayısıyla zaman içinde kansere sebep olabilmektedir $[3,20]$. 


\section{ZONGULDAK HAVZASINDA YAPILMIŞ \\ RADON GAZI ÖLÇÜMLERINIIN DEĞERLENDİRİLMESİ}

\section{Zonguldak taş kömürü havzasında Türkiye Taşkömürü} Kurumu bünyesinde bulunan işletmelerde yapılan radon gazı ölçümlerinin tümü Tablo 1 de verilmiştir. Bu çalışmaların ilki Fişne ve ark. tarafından Zonguldak taş kömürü radon ölçümlerinin yapıldığı çalışma sahasındaki hava akım hızının yüksek olmasından dolayı radon detektör kabının içine giren hava miktarının düşük olmasındandır. Bu sebeple, Yılmaz ve ark. tarafından yapılan çalışma işçi sağlığı açısından radon gazının değerlendirmesinden çok dedektörlerin konumlarının radon gazı ölçümlerine etkisi üzerine olmasından dolayı Tablo 1 e dahil edilmemiştir.

Tablo 1: Zonguldak taşkömürü havzasında bulunan beş işletmede yapılan radon gazı ölçümlerinin karşılaştırılması $[6,9,10]$.

\begin{tabular}{lccl}
\hline İşletme & En düşük ve en yüksek ${ }^{222} \mathbf{R n}$ konsantrasyonu $\left(\mathbf{B q}^{*} / \mathbf{m}^{\mathbf{3}}\right)$ & Ortalama ${ }^{222} \mathbf{R n}$ konsantrasyonu $\left(\mathbf{B q}^{*} / \mathbf{m}^{\mathbf{3}}\right)$ & Referanslar \\
\hline Kozlu & $359-1470$ & 656 & Fişne ve ark. 2004 \\
Karadon & $253-1213$ & 705 & Fişne ve ark. 2004 \\
Üzülmez & $428-1098$ & 672 & Fişne ve ark. 2004 \\
Amasra & $49-223$ & 117.4 & Baldık ve ark. 2005 \\
Armutçuk & $63-706$ & 199,5 & Baldık ve ark. 2009 \\
\hline
\end{tabular}

havzasında bulunan Kozlu, Karadon ve Üzülmez işletmelerinde 6 haftalık süreyle pasif nükleer iz dedektörleri (CR39 plastik iz dedektörleri) kullanılarak gerçekleştirilmiştir [6]. Bu çalışmadan sonra Baldık ve ark. aynı havzada bulunan Amasra işletmesinde benzer bir çalışma gerçekleştirmişlerdir [9]. Zonguldak kömür havzasında bulunan bir diğer işletme Armutçuk kömür madeninde radon gazının mevsimsel değişimini incelemek için Baldık ve ark. tarafından yapılan bir çalışmada 60 gün süreyle CR-39 plastik iz dedektörleri kullanılarak radon gazı ölçümleri yapılmıştır [10]. Yine aynı havzada Yılmaz ve ark. tarafından beş işletmede (Kozlu, Karadon, Üzülmez, Amasra ve Armutçuk) CR-39 plastik iz dedektörlerinin hava akımına dik ya da paralel şekilde konumlanışının ve mevsimsel değişimin radon konsantrasyonu üzerine etkisini araştırmak amacıyla radon konsantrasyon ölçümlerini gerçekleştirmişlerdir [11]. Yılmaz ve ark. tarafından yapılan bu çalışmanın diğer çalışmalardan farkı, ölçümlerin işletmelerin havalandırma galerilerinde yapılmış olmasıdır ve elde edilen bulgular diğer çalışmalara nazaran daha düşük çıkmış olmasıdır [11]. Radon konsantrasyon değerlerinin düşük çıkmasının sebebi,
Tablo 1 deki sonuçları kıyaslamak için limit değerlere ihtiyaç duyulmaktadır. Bu limit değerler Uluslararası Radyasyondan Korunma Komitesinin (ICRP) 65 nolu raporunda işyerleri için $500-1500 \mathrm{~Bq} / \mathrm{m}^{3}$ arasında olması önerilmiştir [24]. Ülkemizde ise Türkiye Atom Enerjisi Kurumu (TAEK) tarafindan yeraltı maden ocaklarında maksimum müsaade edilebilir radon gazı konsantrasyon limiti $1000 \mathrm{~Bq} / \mathrm{m}^{3}$ olarak belirlenmiştir. Zonguldak taşkömürü havzasında yapılan ölçümlerden elde edilen ortalama radon konsantrasyonları, TAEK'in belirlediği müsaade edilebilir limitin altındadır. Ancak Kozlu, Karadon ve Üzülmez işletmelerinin en yüksek konsantrasyon değerlerine bakıldığ zaman $1000 \mathrm{~Bq} / \mathrm{m}^{3}$ değerinin üzerinde olduğu görülmektedir. Bu son değerlendirmeye bakılarak bu işletmelerin yüksek değer elde edilen bölümlerinde çalışanların radon gazından dolayı bir risk altında olduğu sonucuna varmak yanlış olacaktır. Tek başına radon konsantrasyonu ile buna karar verilemez. Bunun için radon gazı sebebiyle maruz kalınan radyasyonun zarar verme derecesi olan doz değerlerine bakılarak ayrıca bir değerlendirme yapılmalıdır. Böyle 
Tablo 2: Zonguldak taşkömürü havzasında bulunan beş işletmede çalısan madencilerin aldığı doz değerleri ve yaşam boyu ölüm riskle-

\begin{tabular}{|c|c|c|c|c|c|c|}
\hline \multirow{2}{*}{ İşletme } & \multicolumn{2}{|c|}{ YED (mSv/y) } & \multicolumn{2}{|c|}{ WLM (WLM/y) } & \multicolumn{2}{|c|}{ Yaşam Boyu Ölüm Riski } \\
\hline & En yüksek & Ortalama & En yüksek & Ortalama & En yüksek & Ortalama \\
\hline Kozlu & 10.58 & 4.72 & 1.85 & 0.83 & $5.55 \times 10^{-4}$ & $2.49 \times 10^{-4}$ \\
\hline Karadon & 8.73 & 5.08 & 1.53 & 0.90 & $4.59 \times 10^{-4}$ & $2.70 \times 10^{-4}$ \\
\hline Üzülmez & 7.91 & 4.84 & 1.38 & 0.85 & $4.14 \times 10^{-4}$ & $2.55 \times 10^{-4}$ \\
\hline Amasra & 1.61 & 0.85 & 0.28 & 0.15 & $0.84 \times 10^{-4(a)}$ & $0.45 \times 10^{-4(a)}$ \\
\hline Armutçuk & 5.08 & 1.44 & 0.89 & 0.25 & $2.67 \times 10^{-4(a)}$ & $0.75 \times 10^{-4(a)}$ \\
\hline
\end{tabular}

(a) Bu değerler ilk kez bu çalışmada hesaplanmıştr.

bir değerlendirme yapmak için Tablo 2 deki doz hesapları incelenmelidir.

Radon ve radon bozunma ürünlerinden alınan yıllık etkin doz (YED) ise madencilerin bir y1l boyunca maruz kaldıkları radyasyonun zararlı biyolojik etkilerinin bir ölçüsünü verecektir. Burada, madencilerin radon ve bozunma ürünlerini solumasıyla aldıkları toplam yıllık etkin doz, yılda 2000 saat çalışıldığı kabul edilerek hesaplanmaktadır (Tablo 2). ICRP 65 nolu raporunda maruz kalınan YED değerini 3-10 mSv/y arasında sınırlandırmıştır [24]. Buna göre, Zonguldak taşkömürü havzasında bulunan Kozlu, Karadon ve Üzülmez işletmelerinde çalışan madencilerin aldığı ortalama YED değerleri ICRP’nin belirlediği limit değerler arasındayken Amasra ve Armutçuk işletmelerinde alt limit olan $3 \mathrm{mSv} / \mathrm{y}$ değerinin altındadır. En yüksek YED değeri göz önüne alındığında ise üst limit değeri 10 mSv/y'yi aşan tek işletmenin Kozlu işletmesi (10.58 mSv/ y) olduğu görülmektedir.

Bir diğer doz değeri olan çalışma düzeyi (working level:WL) ise birim hacim havadaki radon ürünlerinin konsantrasyon birimidir. Radonun bozunma ürünleri Polonyum $\left({ }^{218} \mathrm{Po}\right)$, Kurşun $\left({ }^{214} \mathrm{~Pb}\right)$, Bizmut $\left({ }^{214} \mathrm{Bi}\right)$ ve Polonyum (214Po)'dur. Bu bozunma ürünlerini ihtiva eden havayı soluyan bir kişinin maruz kaldığı radyasyonu bulmak için WL değeri, ortalama nefes alma oranı ve havanın akciğer- lerde kalma oranı ile çarpılmalıdır. Fakat genellikle nefes alma ve solunan havanın akciğerde kalma oranları ihmal edilmektedir. Radon ürünlerinden dolayı maruz kalınan radyasyon, çalışma düzeyi ve zamanın bir fonksiyonu olarak hesaplanmaktadır. Maruz kalma ortalama 173 saat (aylık çalışma süresi) olarak alınır ve maruz kalma değerleri aylık çalışma düzeyi (working level month: WLM) cinsinden ölçülür. 1 WL' lik radon ürünleri konsantrasyonu solunan havanın bir ay içindeki çalışma saatleri ile çarpımı 1 WLM' lik ışınlanmanın ölçüsünü vermektedir $[3,6]$. ICRP 65 nolu raporda, $1 \mathrm{~Bq} / \mathrm{m}^{3}$ radon konsantrasyonuna maruz kalma sonucu radon ürünlerinden alınacak radyasyon dozu miktarı 1.26x10-3 WLM/Bq m³ olarak verilmiştir [24]. WLM/yıl ise maruz kalma hızı ölçmede kullanılan bir birimdir. Radon bozunma ürünlerinin solunması halinde ürünlerin potansiyel zarar verme ölçüsü aylık çalışma düzeyi için ICRP 65 nolu raporu da WLM limit doz değeri 2 WLM/yıl olarak belirlenmiştir [24]. Buna göre, Zonguldak taşkömürü havzasında bulunan beş işletmede çalışan madencilerin radon gazı ürünlerinden dolayı maruz kaldıkları en yüksek ve ortalama radyasyon dozu değerleri (WLM değerleri) ise ICRP'nin belirlediği limit değerin 2 WLM/ y'nin altında olduğu görülmektedir (Tablo 2).

Yaşam boyu ölüm riski (lifetime fatality risk) ise WLM başına ışınlanma süresi ve insan yaşının bir fonksiyonu 
olarak hesaplanmaktadır. Bu değer 18-65 yaş arası çalışanların kronik mesleki ışınlanmasından gelen riskin ifade edilmesinde kullanılır. Radon ve bozunma ürünlerine maruz kalan çalışanların yaşam boyu ölüm riski değerleri ICRP tarafından önerilen ölüm katsayısı $3 \times 10^{-4} \mathrm{WLM}^{-1}$ kullanılarak hesaplanmaktadır [25]. Bu katsayının anlamı şu şekilde açıklanabilir; radon ve bozunma ürünlerinden alınan 1 WLM'lik doz sebebiyle yılda $10 \times 10^{-6}$ vaka meydana geliyorsa 30 yıllık çalışma döneminde 1 WLM doz başına $3 \times 10^{-4}$ vaka meydana gelir [25,26]. ICRP 65 nolu raporunda aylık çalışma düzeyi doz değerini $2 \mathrm{WLM} / \mathrm{yll}$ olarak belirlediğine göre yaşam boyu ölüm riski için bu değerin $6 \times 10^{-4}$ olduğu söylenebilir. Zonguldak taşkömürü havzasında bulunan beş işletme için en yüksek ve ortalama yaşam boyu ölüm risk değerleri $6 \times 10^{-4}$ değerinin altında olduğu Tablo 2'den görülmektedir.

\section{SONUÇLAR}

Radon gazı sebebiyle maruz kalınan radyasyonun zarar verme derecesi olan doz değerlerine bakıldığında Kozlu işletmesinin en yüksek YED değeri dışında diğer doz değerlerinin limit değerlerinin altında olduğu görülmektedir. Ayrıca, Zonguldak taşkömürü havzasında bulunan beş işletme kendi aralarında kıyaslanırsa Fişne ve ark. tarafından üç işletmede (Kozlu, Karadon ve Üzülmez) yapılan çalşmadaki bulgular Amasra ve Armutçuk işletmelerine nazaran daha yüksek olduğu görülmektedir.

Bir maden ocağında radon gazı konsantrayonunu azaltmanın tek yolu iyi bir havalandırma sisteminin olmasıdır. Çünkü yeraltında radon konsantrasyonu yüksek hava çekilerek yerine dışarıdan daha düşük konsantrayonlu havanın ocak içine verilmesi ocak içindeki radon konsantrasyonu azaltılmış olur. Radon gazının ortamdan uzaklaşsırılması açısından Amasra ve Armutçuk işletmelerindeki havalandırma koşullarının iyi durumda olduğu söylenebilir.
Ancak, Kozlu, Karadon ve Üzülmez işletmelerinde yapılan çalışmada elde edilen radon gazı bulgularının daha yüksek çıkmasının havalandırmanın yetersiz olduğu sonucuna varmadan önce önemli bir konuyu ele almak gerekmektedir. Fişne ve ark. tarafından yapılan radon gazı ölçümlerinde plastik plaka üzerindeki alfa izleri manuel olarak mikroskop altında sayılmışır [6]. Amasra ve Armutçuk işletmelerinde ise alfa izleri bir görüntü işleme düzeneği kullanılarak daha hassas bir şekilde sayılmıştır $[9,10]$. Bu düzenek, mikroskoptan görüntüyü alan kamera ve alınan analog görüntüyü dijital hale çeviren işlemci ile donatılmış bir bilgisayardan oluşmaktadır. Kozlu, Karadon ve Üzülmez işletmelerinde bu görüntü işleme düzeneğinin kullanılmasının sebebi çalışmanın yapıldığı tarihte ülkemizde bulunmamasından dolayıdır. Bu sebeple Kozlu, Karadon ve Üzülmez işletmelerinde bu görüntü işleme düzeneğiyle radon gazı ölçümleri tekrarlanarak elde edilen bulgular tekrardan değerlendirilmelidir. Böylece, Zonguldak taşkömürü havzasında bulunan beş işletmenin radon gazı açısından değerlendirilmesi daha doğru olacaktır.

\section{KAYNAKLAR}

[1] UNSCEAR (2000) Sources, Effects and Risks of Ionizing Radiation, Report to General Assembly, United Nations Scientific Committee on the Effects of Atomic Radiation, New York

[2] Arrkan, İ., H. ve Uslu, İ. (2004) Günlük Hayatımızda Radyasyon, Türkiye Atom enerjisi Kuru$\mathrm{mu}$, http://www.taek.gov.tr

[3] Baldık, R (2005) Gökgöl ve Cehennemagzi Mağaraları ile Amasra Taşkömürü işletmesinde Radon-222 ölçümü, YL tezi, Zonguldak Karaelmas Universitesi, Fen Bilimleri Enstitüsü.

[4] Korhonen, P., Kokotti, H., and Kalliokoski, P. (2000) Behaviour of RadonProgenies and Particle Levels During Room Depressurisation, Atmospheric Environment, Vol. 34, pp. 2373-2378. 
[5] Durrani, S., A. and Iliç, R. (1997) Radon Measurement by Etched Track Dedectors, World Scientific, Singapore, pp. 261-313.

[6] Fişne, A., Ökten, G., Çelebi, N., (2004) Radon Concentration Measurements in Bituminous Coal Mines. Radiation Protection Dosimetry (2005) Vol. 113, No. 2, pp. 173-177.

[7] Planiniç, J. Faj, D. Vukoviç, B. Faj, Z. Radoliç, V. and Suveljak, B. (2002) Radon exposure and lung cancer. Journal of Radioanalytical and $\mathrm{Nu}-$ clear Chemistry, Vol. 256, No. 2, pp. 349-352.

[8] Küçüktaș, E. (1996) Maden Ocaklarındaki Radyonüklid Konsantrasyonlarının Birikimi Etkileyen Parametrelere Bağlı Olarak Ölçülmesi, Maruz Kalınan Dozların Analitik Bir Yöntem Geliştirilerek Hesaplanması, Doktora Tezi, Ege Üniversitesi, Nükleer Enerji Enstitüsü, İzmir.

[9] Baldık, R., Aytekin, H., Ataksor, B., Tasdelen, M. (2006) Radon Concentration Measurements in the Amasra Coal Field. Radiat. Prot. Dosim., 118 (1): 122-125.

[10] Baldık, R., Aytekin, H., Çelebi, N. (2009) Radon Fluctuations in the Armutçuk Coal Mine. Fresen. Environ. Bull. 18(1): 87-91.

[11] Yılmaz A., Kürkçüoğlu M. E., Haner B. (2009) Nükleer İz Dedektörlerinin Konumlarının Radon Konsantrasyonu Ölçümleri Üzerine Etkisi. . Ulusal Nükleer Bilimler ve Teknolojileri Kongresi, 6-9 Ekim 2009, Muğla, türkiye

[12] Uzbey S, Tel E, Aytekin H, Albayrak N (2013) Karaelmas Fen ve Mühendislik Dergisi, Çorum İli Yeraltı Kömür Ocaklarında Radon Yoğunluğu Ölçümü 3 (1), 1-5.

[13] Yener, G. and Küçüktaş, E. (1998) Concentrations of radon and decay products in various underground mines in western Turkey and total effective döşe equivalents. The Analyst, Vol. 123, pp. 31-34.

[14] Page, D. and Smith, D.M. (1992) The distribution of radon and its decay products in some UK coal mines. Radiat. Prot. Dosim. 45 (1/4), 163166.

[15] Hewson, G. S. and Ralph, M. I. (1994) An investigation into radiation exposure in underground non-uranium mines in Western Australia. J. Radiol. Prot. 14(4), 359-370.

[16] Rao, K. V., Reddy, B. L., Reddy, P. Y., Ramc- hander, R. B. and Reddy, K. R. (2001) Airborn radon and its progeny levels in the coal mines of Godavarikhani, Andhra Pradesh, India. J. Radiol. Prot. 21, 259-268.

[17] Nejad, M. G., Beitollahi, M. M., Fathabadi, N. And Nasiree, P. (2002) Exposure to 222Rn in ten underground mines in Iran. Radiat. Prot. Dosim. 98(2), 223-225.

[18] Veiga, L. H. S.,Melo, V., Koifman, S. and Amaral, E. C. S. (2004) High radon exposure in a Brazilian underground coal mine. J. Radiol. Prot. 24, 295-305.

[19] Dixon, D. W., Page, D. and Bottom, P. A. (1991) Estimates of Dose from Radon Daughters in UK Mines. Radiat. Prot. Dosim. 36(2/4), 137-141.

[20] Yaşar, S. (1970) Uranyum Madenciliğinde Radyasyon Tehlikeleri, Türkiye Atom Enerjisi Kurumu, İstanbulaytekin

[21] Rao, K., V., Reddy, B. L., and Ramchander, R., B. (2001) Airborn Radon and Its Pongeny Levels in The Coal Mines of Godavarikhani, Journal of Radiological Protection, Vol.21, pp. 259268.

[22] EPA (1992) A Citizen's Guide to Radon, Annual Report, EPA Document 402-K92-001

[23] https://www.memorial.com.tr/saglik-rehberleri/ evinizdeki-radon-gaz-tehlikesinden-korunun/

[24] ICRP, (1993) Protection Against Radon-222 at Home and at Work. ICRP Publication 65. Ann. ICRP 23 (2).

[25] ICRP, (1981) Limits for Inhalation of Radon Daughters by Workers. ICRP Publication 32 . Ann. ICRP 6 (1).

[26] Kant K, Upadhyay SB, Sharma G.S., Chakarvarti S.K. (2006) Radon Dosimetry in Typical Indian Dwellings Using Plastic Track Detectors. Indoor and Built Environment, 15;2:187-191. 
